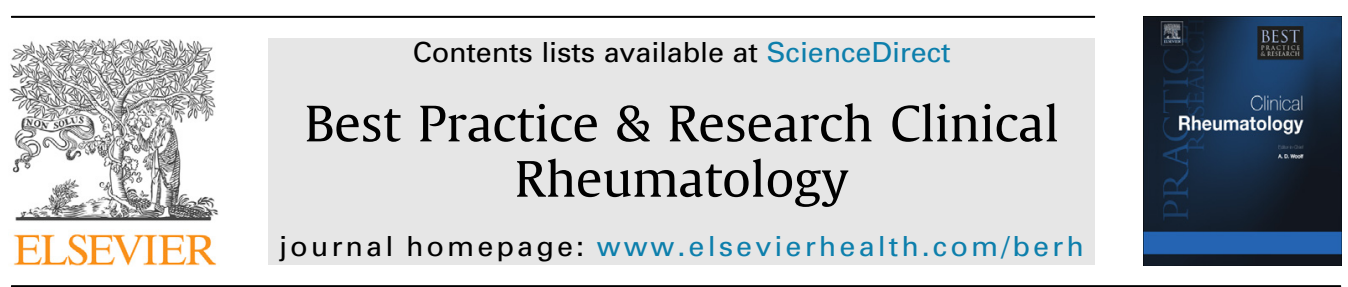

11

\title{
Physical activity in older people - Case studies of how to make change happen
}

\author{
Monica Rodrigues Perracini ${ }^{\text {a, *, }}$ \\ Marcia Rodrigues Costa Franco ${ }^{b}$, Natalia Aquaroni Ricci ${ }^{a}$, \\ Catherine Blake ${ }^{\mathrm{C}}$ \\ ${ }^{a}$ Department of Physical Therapy, Universidade Cidade de São Paulo (UNICID), São Paulo, Brazil \\ ${ }^{\mathrm{b}}$ Faculdade de Ciências e Tecnologia, UNESP-Univ Estadual Paulista, Presidente Prudente, São Paulo, Brazil \\ ${ }^{\mathrm{c}}$ School of Public Health, Physiotherapy and Sports Science, Dublin, Ireland
}

\section{Keywords:}

Older adults

Physical activity

Exercise

Recommendations

Implementation

\begin{abstract}
A B S T R A C T
Enhancing physical activity (PA) is recognized as a powerful intervention for the prevention and treatment of chronic diseases and disability in older people. Furthermore, there is an agreement that increased PA in daily life is a key determinant of active and healthy ageing and should be recommended for frail and sedentary older people. Unfortunately, relatively few older people engage in regular PA or stay active in the long term. This article summarizes and discusses PA recommendations for older adults without focussing on specific diseases, presents the main barriers and facilitators for increasing PA levels, and considers the implementation of these recommendations on the basis of the existing evidence. Finally, we provide case studies of PA programmes for older people that were successfully implemented and highlight the current lessons learned.
\end{abstract}

๑ 2017 Elsevier Ltd. All rights reserved.

\section{Introduction}

Ageing of the population is one of the most significant societal transformations of the 21st century. An estimated $8.5 \%$ (617.1 million) of the total 7.3 billion people worldwide were aged 65 and older in

\footnotetext{
* Corresponding author. Rua Cesáreo Galeno, 448 Tatuapé, São Paulo 03071-000, Brazil.

E-mail addresses: monica.perracini@unicid.edu.br (M.R. Perracini), marciarfranco@gmail.com (M.R.C. Franco), natalia.ricci@ unicid.edu.br (N.A. Ricci), c.blake@ucd.ie (C. Blake).
} 
2015 , but this is projected to grow to $12.0 \%$ ( 1 billion) by 2030 and $16.7 \%$ ( 1.6 billion) by 2050 [1]. Nearly $80 \%$ of the world's older population will live in less developed regions in 2050 [2].

Although people are living longer, they are not necessarily healthier than before. According to the Global Burden of Disease Study, nearly a quarter (23\%) of the overall burden of illness is in people aged over 60 (574 million of the 2490 million disability-adjusted life years [DALYs]; where a DALY expresses the burden of disease as the sum of years of life lost due to dying early and years lost due to disability. Much of this burden is attributable to long-term illnesses caused by diseases, such as cardiovascular disease (30.3\%), cancer (15.1\%), chronic respiratory diseases (9.5\%), musculoskeletal diseases (7.5\%) (such as arthritis and osteoporosis), and mental and neurological disorders (6.6\%) [3]. With longer lifespans, the number of years lived with ill health or disability due to non-communicable diseases (NCDs) and frailty is increasing, and there is currently an estimated average 9 years of healthy life lost globally due to disability [4].

Being physically active is one of the key lifestyle behaviours for health; and physical inactivity is a major contributor to mortality and morbidity in older age. Not only is it associated with cancer [5] cardiovascular disease [6], obesity, and diabetes [7], but physical inactivity itself is a risk factor for all causes of mortality [8]. Furthermore, it is associated with loss of muscle mass and bone density, decrease in balance ability, decrease in muscle strength and endurance, and decline in functional performance, all of which are associated with frailty and loss of independence in older age [9]. The global healthcare costs attributed to physical inactivity for 5 major NCDs (breast and colon cancers, coronary heart disease, stroke, and diabetes) across 142 countries was calculated to be $\$ 53,8$ billion [10]. The effects of physical inactivity on musculoskeletal health are also striking, since fragility fracture is a common end point of declining physical function, sarcopenia, and osteoporosis, all of which are strongly associated with physical inactivity. The cost of fragility fracture is similarly increasing worldwide with 2 million DALYs lost annually in Europe alone [11].

Enhancing physical activity (PA) is recognized as a powerful intervention for the prevention and treatment of chronic diseases and disability in older people [12]. Not only is PA a key recommendation for those robust and active older people, but particularly for those with chronic diseases and disabilities or for those who are already frail or near frail $[12,13]$. Much of the burden due to chronic diseases and related functional impairments and activity limitations is amenable to prevention or treatment with exercise [14]. Furthermore, there is an agreement that increased PA in daily life is a key determinant of active and healthy ageing [15] and should be recommended for frail and sedentary older people [16]. Unfortunately, relatively few older people engage in regular PA or stay active in the long term [14].

Despite the recognized benefits of PA, interventions for increasing PA are generally overlooked by clinical practitioners, frequently in favour of the pharmacologic intervention [17,18]. Amongst other factors, the lack of information regarding the existing evidence and how to implement that evidence in everyday practice may contribute to the under-prescription of exercise and to a more active approach to enhance PA by practitioners [18].

This article summarizes and discusses the PA recommendations for older adults without focussing on specific diseases, present the main barriers and facilitators for increasing PA levels and considers the implementation of these recommendations based on the existing evidence. Finally, we provide case studies of PA programmes for older people that were successfully implemented and highlight the current lessons learned.

The overall aim of this article is to update the recommendations of PA in older adults in general and discuss how to implement them from the clinical practitioner perspective.

\section{Physical activity definition and recommendations}

PA is an overarching term including 'exercise', which may involve structured or planned programmes of specific physical tasks and movements and incidental day-to-day PA, such as housework and gardening. PA includes leisure-time PA, occupational PA, household PA, and transportation PA. People can be physically active without doing exercise; however, greater health benefits are achievable only with the increment of regular exercise [19]. Metabolic equivalents (METs) are commonly used to express the intensity of physical activities. A MET is the ratio of a person's working metabolic rate relative to their resting metabolic rate. One MET is defined as the energy cost of sitting quietly and is 
equivalent to a caloric consumption of $1 \mathrm{kcal} / \mathrm{kg} / \mathrm{hour}$. It is estimated that compared with sitting quietly, a person's caloric consumption is three to six times higher when being moderately active (3-6 METs) and more than six times higher when being vigorously active ( $>6 \mathrm{METs}$ ). Examples of vigorous activity include running, uphill walking, aerobics, fast cycling, carrying a load of $>20 \mathrm{~kg}$, and competitive sports and games. Examples of moderate PA are brisk walking, dancing, gardening, household chores, and carrying loads of $<20 \mathrm{~kg}$ [20]. The benefits that accrue are dependent on the dose of PA achieved, as shown by Rogers et al. (2017) [21]. Compared with the sedentary reference group, mild PA was insufficient to significantly slow the progression of frailty, moderate PA reduced the progression of frailty in some age groups (particularly ages 65 and above), and vigorous activity significantly reduced the trajectory of frailty progression in all older adults. Thus, higher intensity PA is required to effect optimum health benefits [21]. However, the recommendation that some PA is better than none is also valued for older people who cannot meet the amount or intensity of the exercises $[4,12,22]$. There is an agreement that an overall increase in PA in daily life should be recommended for frail and sedentary older people [16]. Particularly, frail older adults living in long-term care facilities may benefit from interventions targeted to increase PA levels as a strategy to optimise physical and cognitive functions. In this sense, staff should be encouraging activities for breaking the sedentary habits, using simple strategies to stimulate residents to move, and motivating residents to increase PA levels using innovative solutions, such as animal interventions and new technologies [23].

For older adults, the American College of Sports Medicine [12,24] and WHO guidelines [25] are consistent in recommending 150 min of moderate intensity aerobic PA (or a combination of vigorous and moderate intensity) and strengthening and balance exercises. Aerobic activity should be performed in sessions of at least 10 min (Box1). These guidelines should be viewed as the minimum amount of activity required to achieve health benefits amongst older adults. Moreover, it is recognized that additional benefits depend on greater amounts of PA. However, the literature is scarce in controlled trials, focussing on the effectiveness of light PA for the older population and on studies evaluating the effect of reducing sedentary behaviour.

Benefits of PA include the following:

- maintenance of balance, strength, flexibility, and exercise capacity,

- maintenance of the ability to live independently and reduction in the risk of falling and fracturing bones,

\section{Box 1}

Global recommendations on PA for health: 65 years and above.

\section{World Health Organisation (WHO, 2010)}

In adults aged 65 years and above, PA includes leisure-time PA (e.g. walking, dancing, gardening, hiking, swimming), transportation (e.g. walking or cycling); occupational (if the individual is still engaged in work), household chores, play, games, sports or planned exercise, in the context of daily, family, and community activities.

To improve cardiorespiratory and muscular fitness, improve bone and functional health, and reduce the risk of NCDs, depression, and cognitive decline, the following are recommended:

Older adults should do at least 150 min of moderate-intensity aerobic PA throughout the week, do at least 75 min of vigorous-intensity aerobic PA throughout the week, or do an equivalent combination of moderate- and vigorousintensity activity.

Aerobic activity should be performed in bouts of at least a 10-min duration each.

For additional health benefits, older adults should increase their moderate-intensity aerobic PA to 300 min per week, engage in 150 min of vigorous-intensity aerobic PA per week, or engage in an equivalent combination of moderate- and vigorous-intensity activity.

Older adults with poor mobility should perform PA to enhance their balance and prevent falls on three or more days per week.

Muscle-strengthening activities, involving major muscle groups, should be done on two or more days a week.

When older adults cannot do the recommended amounts of PA due to health conditions, they should be as physically active as their abilities and conditions allow them to be. 
- reduction in the risk of dying from coronary heart disease and of developing high blood pressure, colon cancer, and diabetes,

- reduction of blood pressure in some people with hypertension,

- improvement of stamina and muscle strength in people with chronic, disabling conditions,

- reduction in anxiety and depression symptoms and fosters improvements in mood and feelings of wellbeing,

- maintenance of healthy bones, muscles, and joints; helps control joint swelling and pain associated with arthritis.

Many older people, however, do not achieve the recommended amount of PA for health benefits [14]. A systematic review synthesised evidence from 53 papers, finding that between $2.4 \%$ and $83.0 \%$ of older adults met recommended PA guidelines across the studies, depending on the sample studied [26]. Older age groups and women were less likely to achieve regular PA, especially leisure time PA, when measured by both subjective and objective criteria. Data from the World Health [15] and SAGE Surveys [27] show a critical increase of the proportion of people not meeting the minimum amount of PA for health with advancing age, as around $45 \%-51 \%$ of men and $55 \%-60 \%$ of women aged 80 years and older did not meet the minimum threshold for health, compared with $19 \%-22 \%$ of men and $25 \%$ of women between 60 and 69 years of age [14]. Prolonged sedentary behaviour also increases with age and is associated with all causes of mortality, metabolic syndrome, and waist circumference amongst people aged 60 and older [28]. Sedentary behaviour is defined as engaging in activities at the resting level of energy expenditure and includes activities such as sleeping, sitting, lying down, reading a book, and watching TV [29]. Older adults spend on average 5.3-9.4 h per waking day in sitting [30]. Curiously, more sedentary behaviour was significantly associated with poorer physical function independent of moderate-vigorous PA levels in adults with radiographic knee osteoarthritis [31]. Though this finding possibly supports that sedentary behaviour is an independent risk factor for poor health outcomes rather than a simple result of less time spent in beneficial moderate activities, the evidence is still limited, particularly for older people. There is a lack of controlled trials focussing on the effectiveness of light PA for older adults as a strategy to reduce sedentary behaviour.

\section{Barriers and facilitators to physical activity amongst older people}

The barriers and facilitators to increasing PA levels and to changing a lifestyle to include regular exercise are multifaceted and complex. The small proportion of older adults engaging in PA programmes and the declining levels of exercise adherence over time have been a concern for clinical practitioners and policy makers. A further challenge is long-term adherence to PA in those who have had exercise counselling and prescriptions. This is not unique to the older population, and attrition is commonly reported over time following PA promotion interventions, irrespective of age. Favourably, a recent review of systematic reviews found that PA-specific interventions (walking, exercise) and nonPA interventions (education, counselling, and motivational interviewing), particularly using tailored interventions, centre-based interventions, and group-based interventions, were effective for increasing short-term uptake of PA amongst the older population [32]. However, the evidence for longterm adherence is still inconclusive due to a lack of studies over a long duration ( $>12$ months). The review results show that facilitators to enhancing PA participation include convenient scheduling and enjoyable activities, whereas barriers to PA include health status, previous PA habits and experiences, and cultural sensitivity [32].

The complexity of a comprehensive understanding regarding factors that influence older people's PA participation and adherence preclude the use of a single research methodology. Particularly, systematic reviews of qualitative studies can identify a range of facilitators and barriers to PA participation from patients' experiences, beliefs, and attitudes, which can help translate the strong evidence of PA benefits into practice. Patients bring valuable insights into the real aspects that enable or prevent participation in health interventions, often overlooked when only the perspectives of clinicians and researches are accounted for [33]. 
In the context of perceptions of older people in the general community regarding PA benefits and barriers, an extensive systematic review of qualitative studies has been published [34]. The systematic review synthetizes the results of 132 studies involving a total of 5987 participants. The studies were conducted in 24 different countries and included older people living in the community and in longterm care facilities, assisted-living facilities, and hospitals. The studies also investigated structured exercise programmes, such as exercises for falls prevention, strength training, yoga and walking groups, and/or other types of physical activities, such as walking and leisure-time PA.

The results of this review [34] show that six major themes and sixteen subthemes influence older people's participation in PA: social influences (valuing interaction with peers, social awkwardness, encouragement from others, dependence on professional instruction), physical limitations (pain or discomfort, concerns about falling, comorbidities), competing priorities, access difficulties (environmental barriers, affordability), personal benefits of PA (strength, balance, flexibility, self-confidence, independence, and improved health and mental well-being), and motivation and beliefs (apathy, irrelevance and inefficacy, maintaining habits). In general, the thematic synthesis showed that though some older people believe in PA's potential to improve physical and mental wellbeing, barriers to PA participation include social support and accessibility. Some older people also believe PA is unnecessary or potentially harmful. Such factors reflect the needs and preferences of older people and are amendable to change. Behavioural strategies that may be used to modify these factors include securing social support from family and friends, promoting participants' self-efficacy and perceived competence, providing older people with active choices tailored to their personal needs and preferences, and encouraging older people to commit to an intervention by developing goal statements that include realistic and measurable action plans with specified health goals. To overcome the misbelief that PA can cause injuries, educational strategies are necessary to raise awareness of PA's health benefits and minimize its perceived risks. Furthermore, these findings suggest that strategies to enhance PA amongst older people must aim to improve environmental and financial access to PA programmes.

Quantitative surveys are also considered an important method to obtain quantitative information from a representative sample. A cross-sectional survey including 1327 older people was conducted to investigate factors that influence older people's participation in a type of PA (i.e., resistance training) [35]. The findings of this survey were similar to the results found in the qualitative systematic review previously cited, showing that "feeling good physically and mentally" was the main motivator for PA participation. Pain, injury, and illness were the main barriers to participating or continuing to participate.

Another contemporary research method that has been used to elicit patients' perspectives in relation to health care interventions is the best-worst scaling choice experiment. This method allows people to choose the best and the worst features (attribute levels) through a series of hypothetical but plausible scenarios [36]. A best-worst scaling study aiming to identify the relative value older people attach to different exercise attributes and levels has been conducted [37]. The results from this study suggest older people place higher value on exercise characteristics than on exercise benefits, and, therefore, their decision on whether or not to engage in exercise programmes is more influenced by programme design and convenience-such as exercise venue, travel time, and out-of-pocket cost$\mathrm{s}$-rather than improvements in health outcomes-such as mobility improvement and risk of falling reduction-provided by the programme. Hence, to effectively increase exercise participation amongst this age group, rather than narrowly focussing on health outcomes like the physical benefits that can be gained with PA, consultations and clinical decision-making must encompass patients' environmental contexts and accessibility to exercise programmes. Clinicians, for instance, should advocate for the provision of low-cost exercise opportunities close to where people live and should prescribe homebased exercises to be performed in multiple short bouts. Moreover, policy makers should facilitate financial and environmental access to exercise programmes.

The results of the studies presented above are illustrated in Table 1 . These findings provide comprehensive information regarding facilitators and barriers to PA participation and evaluate the relative importance older people place on different exercise programme characteristics. Following the current view that patients' values and needs should remain central to the planning and development of health services, these findings can assist health professionals and policy makers when developing strategies to promote PA amongst the older population. (see Table 1). 
Table 1

Barriers to and facilitators of PA participation among older people.

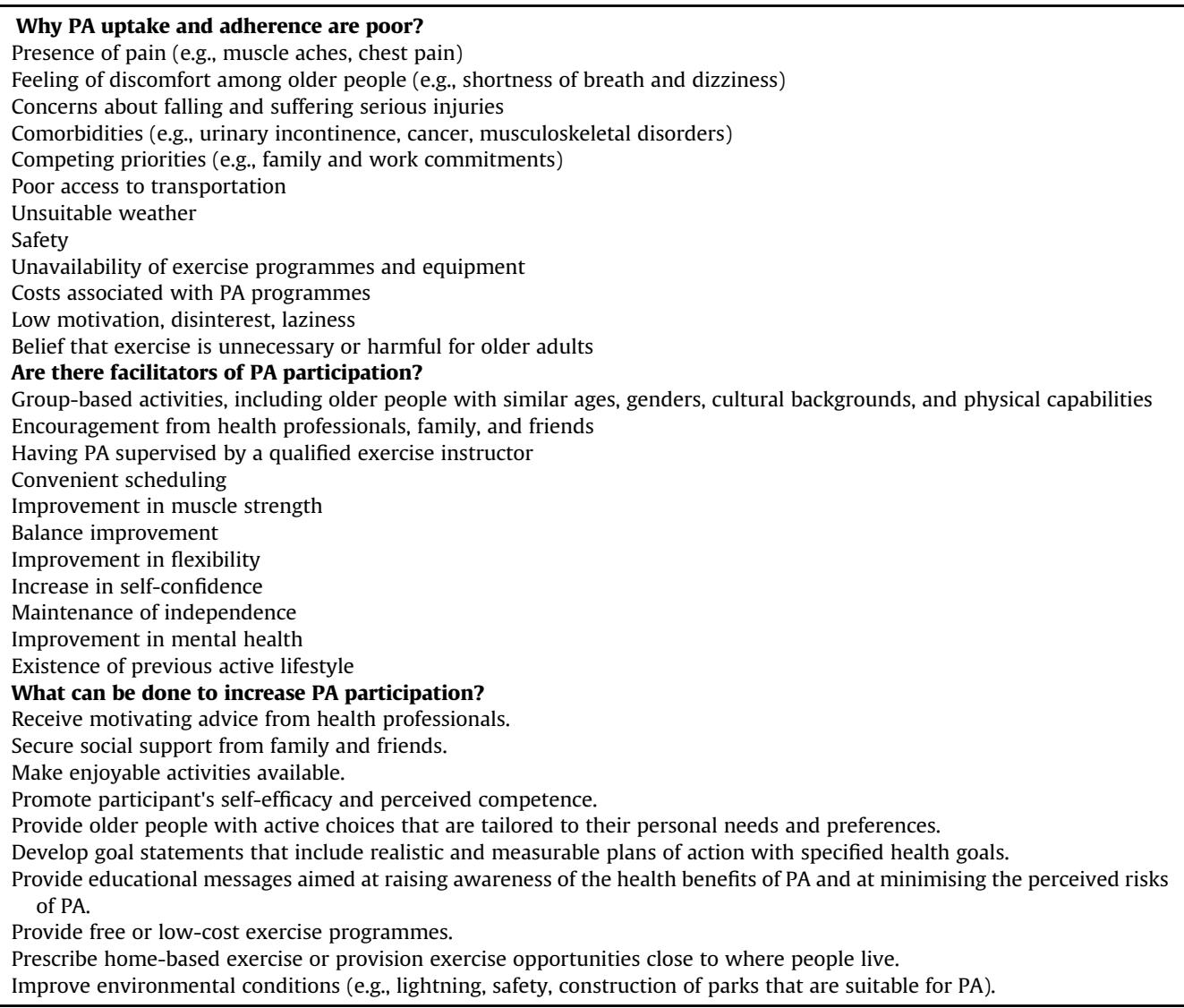

\section{Prescribing PA for older adults: summary of general evidence-based recommendations (Table 2)}

Being as active as possible

Growing evidence exists that having a physically active lifestyle offers a protective benefit against diseases and disability, even if such a lifestyle is not necessarily linked to the recommended moderate and vigorous activity that substantially modifies physical capacity and increase fitness [13]. Being active may involve completing light-intensity activities related to daily life, such as walking to the grocery store, using stairs instead of elevators, and performing household tasks. In a study involving 5575 United States (U.S.) adults, light-intensity PA was inversely associated with all-cause mortality risk, independent of age and other potential confounders [38]. Older adults engaging in $\geq 300 \mathrm{~min} /$ week ( $\geq 5 \mathrm{~h} /$ week) of light-intensity PA presented better body composition measures and metabolic indicators, such as lower C-reactive protein and insulin resistance levels [39]. Although experimental trials involving active lifestyle prescriptions for older adults are lacking, the accumulated results from observational studies have highlighted that getting less than the recommended level of PA still provides health benefits compared with being inactive [40,41]. Further knowledge should be incorporated to establish minimum and maximum thresholds for light-intensity activities, such as how much incidental walking is necessary to achieve a benefit and at what intensity (speed). Without better 
Table 2

General recommendations for increasing PA levels in older people.

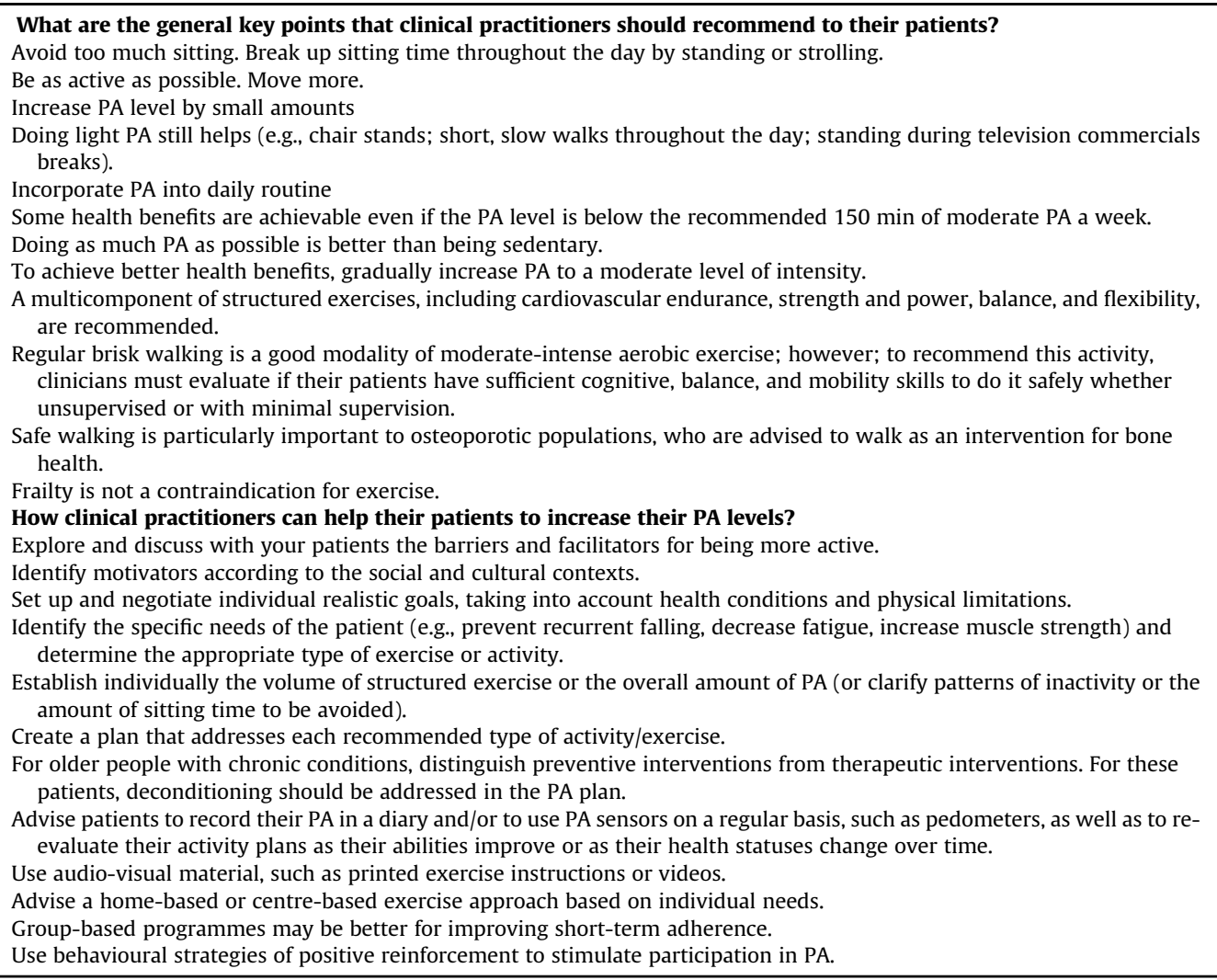

evidence, currently inactive or insufficiently active people should be encouraged to engage in PA, even if it is just light-intensity activity [40]. The encouragement of being as active as possible may promote proactive ageing behaviour, a sense of more 'activeness' that has different patterns according to the individual's social context of active living [42]. This recommendation is in line with a more achievable and updated message of reducing sedentary time and of integrating more light activity into everyday life [43], but it may not necessarily be done at the expense of abandoning the goal of completing $150 \mathrm{~min} /$ week of moderate activity. Clinical practitioners can help older adults to increase their levels of activity by small amounts rather than focussing on the recommended levels [43]. Focussing on only the 150 min a week of moderate-intensity activity may discourage older people from being more active, as they may overlook the benefits of lesser amounts of PA [43].

\section{Elements of prescribing exercise}

Table 3 summarises the elements of structure exercise prescription that is suitable for older adults for addressing different levels of health and fitness. It includes recommendations in terms of intensity, volume, and frequency, and it lists some safety precautions and special features regarding cardiorespiratory, resistance, balance, and the flexibility modalities of exercise. Furthermore, it incorporates some features related to 'active lifestyle' exercises that are broad in terms of components and that are not intended to target a specific physical function [24,44]. Exercise should meet the need of each participant in a tailored basis according to the participant's overall clinical conditions, comorbidities, or multimorbidities as well as the participant's physical and mental functional capacity. Particularly for 
Table 3

Exercise recommendations for the Prevention and Treatment of diseases in Older People.

\begin{tabular}{|c|c|c|c|c|c|}
\hline $\begin{array}{l}\text { Exercise } \\
\text { parameters }\end{array}$ & Active lifestyle & $\begin{array}{l}\text { Cardiovascular endurance } \\
\text { or aerobic training }\end{array}$ & Strength and power & Flexibility & Balance \\
\hline Frequency & $\begin{array}{l}\text { Aerobic training } 5-7 \text { days/ } \\
\text { week } \\
\text { Neuromotor exercise or } \\
\text { functional fitness training: } 2-3 \\
\text { days/week }\end{array}$ & 3-7 days/week & $\begin{array}{l}2-3 \text { days/week } \\
\text { At least } 2 \text { days/week }\end{array}$ & 2-7 days/week & 1-7 days/week \\
\hline Intensity & $\begin{array}{l}\text { Aerobic training: moderate } \\
\text { Neuromotor exercise: not } \\
\text { determined }\end{array}$ & $\begin{array}{l}\text { Moderate to vigorous }-12-13 \\
\text { on Borg Scale (somewhat hard } \\
\text { level of exertion) or } 40 \%-60 \% \\
\text { heart rate reserve or maximal } \\
\text { exercise capacity) } \\
\text { Vigorous training: multiple } 3 \\
-4 \text { min bouts of high intensity } \\
\text { exercise interspersed with } \\
\text { several minutes of low intensity } \\
\text { recovery }\end{array}$ & $\begin{array}{l}\text { Strength }-70-80 \% \\
1 \mathrm{RM}-\text { high intensity, } \\
10 \text { s/repetition, } 1 \text { min } \\
\text { rest between sets } \\
\text { Power }-40-60 \% 1 \mathrm{RM} \\
\text { - low and moderate } \\
\text { intensity and high } \\
\text { velocity }\end{array}$ & $\begin{array}{l}\text { Progressive } \\
\text { neuromuscular } \\
\text { facilitation techniques }\end{array}$ & $\begin{array}{l}\text { Exercise must provide a } \\
\text { moderate or high } \\
\text { challenge to balance. } \\
\text { Exercises should aim to } \\
\text { challenge balance in } \\
\text { three ways: } \\
\text { - reducing the base of } \\
\text { support } \\
\text { - moving the centre of } \\
\text { gravity } \\
\text { - reducing the need for } \\
\text { upper limb support }\end{array}$ \\
\hline Volume & $\begin{array}{l}\text { Aerobic training: at least } 30 \mathrm{~min} \\
\text { accumulated in bouts of } 10 \mathrm{~min} \\
\text { or longer } \\
\text { Neuromotor exercise: } 20 \\
-30 \mathrm{~min} / \text { session }\end{array}$ & $\begin{array}{l}20 \text { to } 60 \mathrm{~min} / \text { session preferably } \\
\text { consecutively with short } \\
\text { periods of rest if needed } \\
\text { At least } 150 \text { min a week of } \\
\text { moderate intensity activity or } \\
30 \text { min five days a week; or } \\
75 \text { min of vigorous intensity } \\
\text { activity spread across the week. }\end{array}$ & $2-3$ sets of $8-10$ reps & $\begin{array}{l}\text { Major muscle groups } \\
1 \text { sustained static } \\
\text { stretch }(20 \mathrm{~s}) \text { of each to } \\
\text { the point of tightness or } \\
\text { slight discomfort }\end{array}$ & $\begin{array}{l}\text { Exercise should be } \\
\text { undertaken for at least } \\
2 \text { h per week }\end{array}$ \\
\hline $\begin{array}{l}\text { Safety } \\
\text { precautions }\end{array}$ & $\begin{array}{l}\text { Begin with low intensity } \\
\text { physical activities and } \\
\text { progressively increase } \\
\text { Low intensity activities: } 1.5 \text { to } \\
2.5 \text { METs } \\
\text { Moderate: } 3.0 \text { to } 6.0 \text { METs }\end{array}$ & $\begin{array}{l}\text { Low impact activities } \\
\text { Increase intensity progressively } \\
\text { (use the Borg Rating of } \\
\text { Perceived Exertion Scale for } \\
\text { monitoring and progressing) }\end{array}$ & $\begin{array}{l}\text { Frail individuals should } \\
\text { begin at low speed, no } \\
\text { ballistic movements } \\
\text { and progressively } \\
\text { increase the speed and } \\
\text { or resistance } \\
\text { No breath holding, } \\
\text { Valsalva manuever } \\
1 \text { day of rest between } \\
\text { sessions }\end{array}$ & $\begin{array}{l}\text { Load should be } \\
\text { carefully applied for } \\
\text { those with osteoporosis } \\
\text { Ballistic stretching } \\
\text { should be avoided } \\
\text { Pain intensity should be } \\
\text { monitored over the } \\
\text { stretching. }\end{array}$ & $\begin{array}{l}\text { High-risk individuals } \\
\text { should not be } \\
\text { prescribed brisk } \\
\text { walking programs } \\
\text { Home-based balance } \\
\text { exercises should be } \\
\text { supervised in frail older } \\
\text { people } \\
\text { More intensive, } \\
\text { supervised exercise } \\
\text { intervention is required } \\
\text { in frail older adults with } \\
\text { high risk for falling, } \\
\text { along with an }\end{array}$ \\
\hline
\end{tabular}




\begin{tabular}{|c|c|c|c|c|c|}
\hline $\begin{array}{l}\text { Exercise } \\
\text { parameters }\end{array}$ & Active lifestyle & $\begin{array}{l}\text { Cardiovascular endurance } \\
\text { or aerobic training }\end{array}$ & Strength and power & Flexibility & Balance \\
\hline $\begin{array}{l}\text { Special } \\
\text { features }\end{array}$ & $\begin{array}{l}\text { It can be incorporated into or } \\
\text { added to the endurance for long } \\
\text { term adherence } \\
\text { Exercises should involve motor } \\
\text { skills (balance, agility, } \\
\text { coordination and gait), } \\
\text { proprioceptive exercise } \\
\text { training and multifaceted } \\
\text { activities (tai ji and yoga) to } \\
\text { improve physical function and } \\
\text { prevent falls in older adults }\end{array}$ & $\begin{array}{l}\text { Most health outcomes appear } \\
\text { to be achievable with moderate } \\
\text { levels of exercise (60\% of heart } \\
\text { rate reserve or maximal } \\
\text { exercise capacity) } \\
\text { Always incorporate weight- } \\
\text { bearing if possible (walking, } \\
\text { standing) }\end{array}$ & $\begin{array}{l}\text { Increase weight } \\
\text { progressively to } \\
\text { maintain relative } \\
\text { intensity } \\
\text { Resistance that } \\
\text { movement overloads } \\
\text { with greater resistance } \\
\text { has a greater effect }\end{array}$ & $\begin{array}{l}\text { As a potential acute } \\
\text { negative effect of } \\
\text { stretching on strength, } \\
\text { stretches should be } \\
\text { held for at maximum } \\
45 \mathrm{~s}\end{array}$ & $\begin{array}{l}\text { educational/ } \\
\text { behavioural program } \\
\text { Walking training may } \\
\text { be included in a } \\
\text { program as long as it is } \\
\text { not at the expense of } \\
\text { balance training } \\
\text { Other risk factors for } \\
\text { falling not amenable to } \\
\text { change with exercise } \\
\text { should be addressed } \\
\text { Tai Chi is less effective } \\
\text { in higher-risk } \\
\text { populations }\end{array}$ \\
\hline
\end{tabular}

With input from: Singh 2002; Cress, Buchner, Prohaska, Rimmer, Brown, \& Macera et al. 2005; Garber, Blissmer, Deschenes, Franklin, Lamonte \& Lee et al. 2011; Stathokostas, Little, Vandervoort \& Paterson 2012; Reid, Martin, Doros, Clark, Hau \& Patten 2015; Sherrington \& Tiedemann 2015; Sparkling, Howard, Dunstan \& Owen 2015.

1 MET is considered a resting metabolic rate obtained during quiet sitting. Examples of low intensity PA in METs: mild stretching; household tasks all at once, light effort; watering plants; walking slow pace, strolling, in the level ground, less than $2 \mathrm{mph}$ or $0.90 \mathrm{~m} / \mathrm{s}$; walking in the neighborhoods for social reason. Examples of moderate intensity PA in METs: walking at a moderate or brisk pace of $3-4.5 \mathrm{mph}$ or $1.3-2.0 \mathrm{~m} / \mathrm{s}$ on a level surface inside or outside, such as walking the dog, walking to store, mopping and vacuuming; water aerobics; stationary bicycling using moderate effort; dancing; yoga; gymnastics, weight training using free weights, tennis - doubles, golfing. CDC 2015. Retrieved from: https://www.cdc.gov/nccdphp/dnpa/ physical/pdf/pa_intensity_table_2_1.pdf.

$1 \mathrm{RM}$ is the maximum amount of force that can be generated in one maximal contraction. 
frail older people, evidence of the effectiveness of exercise in terms of its characteristics (type, frequency, intensity, duration, setting, combinations) is uncertain [45]. The majority of studies involving this population have applied a multicomponent exercise programme with different approaches regarding the components of exercise, thus making comparisons difficult. However, moderate evidence exists to support exercise training in this population for improving walking speed and lower limb functionality, but inconclusive results are available for supporting the use of exercise to improve mobility and balance in frail older people [45].

Muscle weakness is related to sarcopenia, which is one of the most important components of frailty syndrome. Accumulated evidence exists that resistance training interventions, at moderate to high intensity, have been shown to improve sarcopenia, bone mass, cardiometabolic health, and hip fracture recovery, amongst others [14]. Although better results are linked to high-intensity progressive resistance strength training, this exercise modality is considered safe [46]. The treatment of mobility disability related to frailty demands a long-term structured PA programme that includes not only resistance training but also endurance and flexibility [47]. As frail older people are at a higher risk of falling, balance training is also important. An increase in muscle mass and in strength as a result of progressive resistance training has a positive effect on aerobic capacity and balance. However, walking as a natural choice of exercise in frail older adults cannot increase balance skills and prevent falls [48]. Functional balance training is not capable of improving strength or endurance.

\section{Home based or centre based}

The better setting for PA delivery is yet somewhat controversial and needs to be better studied, particularly regarding long-term adherence and cost-effectiveness. Home-based programmes seem to offer some positive features, such as no need for transportation, more convenience related to flexible schedules, and the use of familiar amenities. However, competing demands from family and household tasks, and a lack of supervision and insecurity regarding the execution of exercises may result in some concerns for older adults and their caregivers. On the other hand, centre-based programmes may offer better and more sophisticated equipment, offer more close supervision, and motivate people to socialize. The decision regarding the best setting for engaging in a PA programme should be based on older adults' preferences, perceived barriers and facilitators, physical and cognitive health, mobility capacity, and social support.

The existing evidence shows that both centre-based and home-based interventions have resulted in significant improvements in functional activity in people aged 50 years and older with cardiovascular diseases, but not in people with chronic obstructive pulmonary disease. However, the long-term impact of the setting on functional capacity cannot be determined, as no studies have evaluated impact beyond six months. Although much more research is needed, at this time, community programmes for community-dwelling adults should consider centre- and home-based programmes in combination. Centre-based programmes have achieved good adherence in the short term and greater effects on PA behaviour change. However, home-based activity programmes should be recommended given the better long-term adherence to them compared to centre-based programmes [49]. The magnitude of the difference of PA between settings is somewhat controversial. PA delivered at the participant's house showed a higher effect size compared with PA delivered in a community setting or at a clinic setting in one systematic review [50], but the opposite was observed in a second review in which studies testing centre-based exercise reported significantly larger effect sizes than did studies with home-based exercises [32].

\section{Mode of intervention}

Although some older adults may feel uncomfortable with doing exercises in front of others, interventions delivered in group sessions may promote social interaction, increase self-efficacy and resilience, and welcome the positive and negative experiences of participants with unique life trajectories. PA interventions delivered in a group format are found to be effective, increasing short-term participation by a mean of $84 \%$ (55-100\%) but with a decline after one year [51]. Different approaches to changing PA behaviour vary from general counselling to active coaching [52]. Recent findings 
suggest that older adults respond better to combined interventions based on cognitive processes (e.g., education, counselling) and behavioural-type strategies (e.g., self-monitoring, goal setting) to change their PA behaviour [52]. These strategies are frequently based on theoretical models, such as the social cognitive theory that Bandura developed. Positive associations between theory-based interventions and short-term PA uptake have been observed, with the training and expertise of health care professionals being deemed valuable for delivering appropriate techniques for changing behaviour. These behavioural-based interventions include participating in supervised exercise sessions, motivational interviewing and goal setting, and self-monitoring. Particularly, goal setting and self-monitoring showed some success when applied in combination with the use of a pedometer and a PA diary. Those older people who set their goals for increasing the total steps count by $30 \%$ and monitored their performance in a daily basis presented a $23 \%$ increase in daily steps compared with the education group that decreased the daily steps by $15 \%$. Cognitive-behavioural tailored interventions, particularly motivational interviewing strategies, reported more successful long-term results [32,52].

The use of audio-visual or mailed materials were effective in increasing PA behaviour. The types of audio-visual materials used in primary studies included discs of music or exercise instruction, and exercise videos. Informational newsletters and descriptive examples of exercises are examples of mailed materials. The use of lectures or other forms restricted to verbal information was comparatively less effective in increasing PA. However, future research may compare face-to-face interventions with those delivered only through audio-visual and/or printed materials [52].

Technology has been substantially incorporated in PA programmes to monitor and progressively set up goals for increasing PA levels over time (pedometers and accelerometers); to provide technology group-based exercises (exergames); and to deliver structured exercises, such as balance rehabilitation programmes as well as endurance and general fitness programmes using virtual reality. Evidence shows that technology offers a safe and well-accepted method for providing independent older adults living in the community with exercise opportunities that are enjoyable and motivating [53]. Under supervision, technology-based exercise programmes showed slightly better adherence rates than did traditional exercise programmes in this population. However, at unsupervised settings, adherence rates favoured technology-based exercise programmes, but all studies are of short duration, and longterm adherence has not been investigated [53].

\section{Case studies: successful implementation of PA programmes for older people}

At the individual level, the challenge is to find suitable and achievable ways of enhancing and sustaining PA levels, and to avoid physical inactivity and too much sitting. Walking is generally considered the entry-level activity for safe and effective exercise prescription for sedentary older adults, with a gradual increase in speed or intensity of exertion over time [17]. In this sense, our first case of successful implementation is a combined intervention for increasing PA through a walking programme called the PACE (Pedometer Accelerometer Consultation Evaluation) Lift [54], which is described in Box 2. The programme used a pedometer walking-based intervention, plus the use of accelerometers for objectively determining the amount of PA, plus nurse consultations based on behavioural cognitive techniques (BCTs) and the use of a handbook for recording goals and monitoring results. Although accelerometers are not commonly available in clinical practice, an important message taken from its use is the need to personalize PA goals over time and to increase the level of activity gradually and progressively. In this programme pedometers were used as an objective measure of the amount of PA being performed, which may have stimulated participants to increase their number of steps and the frequency of 10-min bouts of moderate physical exercise. Participants particularly valued BCTs that nurses delivered. Although this intervention demands training and a certain level of experience, some important messages can be delivered through counselling, and clinical practitioners may be aware of the importance of developing skills for changing patients' behaviour [17]. The first step is to ask about PA and to understand from the patient's point of view what the barriers and possible facilitators for increasing PA are. (see Box 3).

The second successful case is the Lifestyle integrated Functional Exercise (LiFE) programme [55], which proposes movements specifically prescribed for improving balance or increasing strength that are embedded within everyday activities. The programme rationale is to provide opportunities for 


\section{Box 2}

Case 1 - PACE (Pedometer Accelerometer Consultation Evaluation) Lift.

Population: youngest-old (60-75 years) community-dwellers registered at general practices that could walk outdoors and had no contraindications to increase PA

Intervention: intervention components delivered by nurses based on individual walking plan (goal of at least $150 \mathrm{~min}$ of moderate PA for week, adding up to bouts of $10 \mathrm{~min}$ ) + pedometers + accelerometers + practice consultations based on key BCTs, including goal setting, self-monitoring, building self-efficacy and social support, overcoming barriers, preventing relapses, and building lasting habits, +PACE Lift patient handbook, which supported behavioural cognitive thecniques (BCTs) + a PA diary for recording PA and step counts, used with the sensors to set goals, monitor progress, and aid in providing feedback by relating specific diary activities to accelerometer-recorded PA intensities. Nurses encouraged steps and time spent walking in moderateintensity PA, particularly in bouts of at least $10 \mathrm{~min}$, to be added incrementally to each individual's baseline. Nurses also encouraged discussion of when participants would walk, to where, and with whom.

Positive results: increased step counts, in time spent in moderate to Vigorous PA (MVPA) and in bouts of MVPA of at least $10 \mathrm{~min}$ at 3 months and at 12 months. There was long-term participation ( $90 \%$ retention rate at 12 months). More than $50 \%$ of the difference at 3 months was maintained at

12 months and 9 months post-intervention.

Important characteristics for success:

- Tailored PA goals based on technology information (accelerometers);

- PA level was increased progressively and continuously based on self-monitoring;

- Use of cognitive behavioural techniques and printed material (handbook);

- Use of an individualised PA plan based on the person's baseline (starting low and going slow');

- Nurses were trained to use BCTs, to use technology, prescribe exercise, chart progress, set goals, and solve problems;

- Barriers to increasing PA levels were explored and discussed; and

- Practical things related to walking were discussed, such as when participants would walk, to where, and with whom.

training multiple times during the day (e.g., squatting instead of bending at the waist to close a drawer, which can be upgraded to picking things up from the floor). LiFE training focuses on instituting new habitual behaviours within selected situational contexts that serve as prompts for action. The programme was prescribed, tailored, and upgraded through sessions, and printed material (manuals) described each balance and strength strategy across a range of daily activities and situations, with ideas for increasing intensity and challenge. Thus, the manuals were used in the teaching and planning of the

\section{Box 3}

\section{Case 2 - Lifestyle Integrated Functional Exercise (LiFE) Programme}

Population: men and women aged 70 years or older and who had two or more falls or one injurious fall in the past 12 months

Intervention: Movements specifically prescribed to improve balance or increase strength are embedded within everyday activities (e.g., assume a tandem stand while working at the kitchen bench, and over time, upgrade to working while standing on one leg). Everyday activities that were altered for LiFe participants were determined through self-report using a weekly planner and interview.

Positive results: a clinically important reduction of $31 \%$ in the rate of falls for participants in the LiFE programme Important characteristics for success:

- Tailored approach to embedded exercise with functional activity;

- PA intensity was increased progressively and continuously based on self-monitoring;

- PA planning discussed with participants (participants' involvement);

- Self-monitoring and the use of a weekly planner; and

- Use of sessions for upgrading, discussing, and monitoring PA. 
Table 4

Main research gaps in increasing PA for older adults.

What are the key gaps for improving the PA levels in this population?

What is the impact of physical activity for special older populations (with low socioeconomic status, ethnic/racial minorities, persons with physical disabilities, persons with intellectual disabilities and persons with mental illness)?

What is the light-intensity PA dose-response for achieving health benefits, for improving functional capacity, and for preventing disability?

Which combination of light-intensity activities is most effective?

Are those who increase their light-intensity PA more likely to engage in more intense PA in the future?

Is the promotion of more intense PA in primary care effective?

Is the combination of behavioural and cognitive strategies more effective than behavioural or cognitive strategies alone?

What theoretical concepts are linked with specific intervention components and study designs?

What theoretical constructs may promote changes in behavioural outcomes?

Are interventions delivered via audio-visual methods more effective than those delivered via mailed mechanisms?

Are interventions delivered via audio-visual methods more effective than those delivered face-to face?

Are PA interventions delivered via the use of technologies effective?

What are effective interventions for long-term PA change?

What are the costs and cost-effectiveness of PA interventions?

individualised programme. The lessons learned from this programme are the need to find ways of incorporating PA into daily life on a very individualised basis and to gradually upgrade PA intensity. Tailored and embedded activity based on patients' functional conditions could enhance the integration of skills and maintain exercise adherence [55].

\section{Summary}

Much remains to be investigated to provide stronger, clear, and direct evidence-based strategies for enhancing and sustaining PA levels in older adults with different levels of functioning (Table 4). However, the existing knowledge already provides directions for practitioners to responsibly plan PA interventions over time. Furthermore, many lessons have been learned from successful programmes that can help clinicians to personalise PA and to achieve health benefits. The main lesson is that older adults, frail and non-frail, should be encouraged and enabled to increase their activity levels based on concrete and achievable goals.

\section{Conflict of interest statement}

The authors declare that they have no competing interests.

\section{References}

[1] DESA U. World population prospects: the 2015 revision, key findings and advance tables. In: United Nations DoEaSA, population division editor. World population prospects: the 2015 revision, key findings and advance tables. United Nations: Department of Economic and Social Affairs, Population Division; 2015.

[2] DESA U. World population ageing 2015. In: United Nations DoEaSA, population division editor; 2015.

[3] Prince M, Wu F, Guo Y, et al. The burden of disease in older people and implications for health policy and practice. Lancet 2015;385(9967):549-62.

[4] WHO. World report on ageing and health. Geneva: World Health Organization; 2015.

[5] Moore S, Lee I, Weiderpass E, et al. Association of leisure-time PA with risk of 26 types of cancer in 1.44 million adults. JAMA Intern Med 2016;176(6):816-25.

[6] Li J, Siegrist J. PA and risk of cardiovascular disease-a meta-analysis of prospective cohort studies. Int J Environ Res Public Health 2012;9(2):391-407.

[7] Venables M, Jeukendrup A. Physical inactivity and obesity: links with insulin resistance and type 2 diabetes mellitus. Diabetes Metab Res Rev 2009;25(Suppl. 1):S18-23.

[8] Andersen L, Schnohr P, Schroll M, Hein H. All-cause mortality associated with physical activity during leisure time, work, sports, and cycling to work. Arch Intern Med 2000;160(11):1621-8.

[9] Marzetti E, Calvani R, Tosato M, et al. Physical activity and exercise as countermeasures to physical frailty and sarcopenia. Aging Clin Exp Res 2017;29(1):35-42.

[10] Ding D, Lawson K, Kolbe-Alexander T, et al. The economic burden of physical inactivity: a global analysis of major noncommunicable diseases. Lancet 2016;388(10051):1311-24. 
[11] Hernlund E, Svedbom A, Ivergard M, et al. Osteoporosis in the European Union: medical management, epidemiology and economic burden. A report prepared in collaboration with the International Osteoporosis Foundation (IOF) and the European Federation of Pharmaceutical Industry Associations (EFPIA). Arch Osteoporos 2013;8:136.

*[12] American College of Sports M, Chodzko-Zajko W, Proctor D, et al. American College of Sports Medicine position stand. Exercise and physical activity for older adults. Med Sci Sports Exerc 2009;41(7):1510-30.

[13] Singh M. Exercise comes of age: rationale and recommendations for a geriatric exercise prescription. J Gerontol A Biol Sci Med Sci 2002;57(5):M262-82.

*[14] Bauman A, Merom D, Bull F, Buchner D, Fiatarone Singh M. Updating the evidence for physical activity: summative reviews of the epidemiological evidence, prevalence, and interventions to promote "active aging". Gerontologist 2016; 56(Suppl. 2):S268-80.

[15] WHO. Active ageing: a policy framework. World Health Organization; 2002.

[16] Cruz-Jentoft A, Landi F, Schneider S, et al. Prevalence of and interventions for sarcopenia in ageing adults: a systematic review. Report of the International Sarcopenia Initiative (EWGSOP and IWGS). Age Ageing 2014;43(6):748-59.

*[17] Sallis R, Matuszak J, Baggish A, et al. Call to action on making physical activity assessment and prescription a medical standard of care. Curr Sports Med Rep 2016;15(3):207-14.

[18] Persson G, Brorsson A, Ekvall Hansson E, Troein M, Strandberg E. Physical activity on prescription (PAP) from the general practitioner's perspective - a qualitative study. BMC Fam Pract 2013;14:128.

[19] Brach JS, Simonsick EM, Kritchevsky S, et al. The association between physical function and lifestyle activity and exercise in the health, aging and body composition study. J Am Geriatr Soc 2004;52(4):502-9.

[20] Centers for Disease Control and Prevention. General physical activities defined by level of intensity. 2017. Retrieved from https://www.cdc.gov/nccdphp/dnpa/physical/pdf/PA_Intensity_table_2_1.pdf.

[21] Rogers N, Marshall A, Roberts C, Demakakos P, Steptoe A, Scholes S. Physical activity and trajectories of frailty among older adults: evidence from the English Longitudinal Study of Ageing. PLoS One 2017;12(2):e0170878.

*[22] WHO. Physical activity and older adults: recommended levels of physical activity for adults aged 65 and above. World Health Organization; 2010.

[23] de Souto Barreto P, Morley JE, Chodzko-Zajko W, et al. Recommendations on physical activity and exercise for older adults living in long-term care facilities: a taskforce report. J Am Med Dir Assoc 2016;17(5):381-92.

*[24] Garber C, Blissmer B, Deschenes M, et al. American College of Sports Medicine position stand. Quantity and quality of exercise for developing and maintaining cardiorespiratory, musculoskeletal, and neuromotor fitness in apparently healthy adults: guidance for prescribing exercise. Med Sci Sports Exerc 2011;43(7):1334-59.

[25] WHO. Information sheet: global recommendations on physical activity for health 65 years and above. World Health Organization; 2011.

[26] Sun F, Norman I, While A. Physical activity in older people: a systematic review. BMC Public Health 2013;13:449.

[27] WHO. WHO study on global AGEing and adult health (SAGE 2007-2010). World Health Organization; 2010.

[28] de Rezende LF, Rey-Lopez JP, Matsudo VK, do Carmo Luiz O. Sedentary behavior and health outcomes among older adults: a systematic review. BMC Public Health 2014;14:333.

[29] Pate R, O'Neill J, Lobelo F. The evolving definition of "sedentary". Exerc Sport Sci Rev 2008;36(4):173-8.

[30] Harvey JA, Chastin SF, Skelton DA. How sedentary are older people? A systematic review of the amount of sedentary behavior. J Aging Phys Act 2015;23(3):471-87.

[31] Lee J, Chang R, Ehrlich-Jones L, et al. Sedentary behavior and physical function: objective evidence from the osteoarthritis initiative. Arthr Care Res Hob 2015;67(3):366-73.

*[32] Olanrewaju O, Kelly S, Cowan A, Brayne C, Lafortune L. Physical activity in community dwelling older people: a systematic review of reviews of interventions and context. PLoS One 2016;11(12):e0168614.

[33] Facey K, Boivin A, Gracia J, et al. Patients' perspectives in health technology assessment: a route to robust evidence and fair deliberation. Int J Technol Assess Health Care 2010;26(3):334-40.

*[34] Franco MR, Tong A, Howard K, et al. Older people's perspectives on participation in physical activity: a systematic review and thematic synthesis of qualitative literature. Br J Sports Med 2015;49(19):1268-76.

[35] Burton ELG, Farrier K, Lewin G G, et al. Motivators and barriers for older people participating in resistance training: a systematic review. Aging Phys Act 2017;25(2):311-24.

[36] Flynn TN, Louviere JJ, Peters TJ, Coast J. Best-worst scaling: what it can do for health care research and how to do it. J Health Econ 2007;26(1):171-89.

[37] Franco MR, Howard K, Sherrington C, et al. Eliciting older people's preferences for exercise programs: a best-worst scaling choice experiment. J Physiother 2015;61(1):34-41.

[38] Loprinzi PD. Light-itensity physical activity and all-cause mortality. J Health Promot 2017;31(4):340-2.

[39] Loprinzi P, Lee H, Cardinal B. Evidence to support including lifestyle light-intensity recommendations in physical activity guidelines for older adults. Am J Health Promot 2015;29(5):277-84.

[40] Fuzeki E, Engeroff T, Banzer W. Health benefits of light-intensity physical activity: a systematic review of accelerometer data of the National Health and Nutrition Examination Survey (NHANES). Sports Med 2017.

[41] Hamer M, de Oliveira C, Demakakos P. Non-exercise physical activity and survival: English longitudinal study of ageing. Am J Prev Med 2014;47:452-60.

[42] Guell C, Shefer G, Griffin S, Ogilvie D. 'Keeping your body and mind active': an ethnographic study of aspirations for healthy ageing. BMJ Open 2016;6(1):e009973.

*[43] Sparling P, Howard B, Dunstan D, Owen N. Recommendations for physical activity in older adults. BMJ 2015;350:h100.

[44] Cress M, Buchner D, Prohaska T, et al. Best practices for physical activity programs and behavior counseling in older adult populations. J Aging Phys Act 2005;13(1):61-74.

[45] Gine-Garriga M, Roque-Figuls M, Coll-Planas L, Sitja-Rabert M, Salva A. Physical exercise interventions for improving performance-based measures of physical function in community-dwelling, frail older adults: a systematic review and meta-analysis. Arch Phys Med Rehabil 2014;95(4). 753-769. e3. 
[46] Raymond M, Bramley-Tzerefos R, Jeffs K, Winter A, Holland A. Systematic review of high-intensity progressive resistance strength training of the lower limb compared with other intensities of strength training in older adults. Arch Phys Med Rehabil 2013;94(8):1458-72.

[47] Pahor M, Guralnik J, Ambrosius W, et al. Effect of structured physical activity on prevention of major mobility disability in older adults: the LIFE study randomized clinical trial. JAMA 2014;311(23):2387-96.

[48] Voukelatos A, Merom D, Sherrington C, Rissel C, Cumming R, Lord S. The impact of a home-based walking programme on falls in older people: the easy steps randomised controlled trial. Age Ageing 2015;44(3):377-83.

[49] Ashworth N, Chad K, Harrison E, Reeder B, Marshall S. Home versus center based physical activity programs in older adults. Cochrane Database Syst Rev 2005;(1):CD004017.

*[50] Chase J. Interventions to increase physical activity among older adults: a meta-analysis. Gerontologist 2015;55(4): $706-18$.

[51] van der Bij A, Laurant M, Wensing M. Effectiveness of physical activity interventions for older adults: a review. Am J Prev Med 2002;22(2):120-33.

*[52] Chase J. Physical activity interventions among older adults: a literature review. Res Theory Nurs Pract 2013;27(1):53-80.

[53] Valenzuela T, Okubo Y, Woodbury A, Lord S, Delbaere K. Adherence to technology-based exercise programs in older adults: a systematic review. Geriatr Phys Ther 2016;00:1-13.

[54] Harris T, Kerry SM, Victor CR, et al. A primary care nurse-delivered walking intervention in older adults: PACE (pedometer accelerometer consultation evaluation)-lift cluster randomised controlled trial. PLoS Med 2015;12(2):e1001783.

[55] Clemson L, Fiatarone Singh M, Bundy A, et al. Integration of balance and strength training into daily life activity to reduce rate of falls in older people (the LiFE study): randomised parallel trial. BMJ 2012;345:e4547. 